\title{
OPTICAL PROPERTIES OF MATERIALS FOR CONCENTRATOR PHOTOVOLTAIC SYSTEMS
}

R. H. French ${ }^{1}$, J. M. Rodríguez-Parada ${ }^{1}$, M. K. Yang ${ }^{1}$, R. A. Derryberry ${ }^{1}$, M. F. Lemon ${ }^{1}$, M. J. Brown ${ }^{2}$, C. R. Haeger ${ }^{3}$, S. L. Samuels ${ }^{4}$, E. C. Romano ${ }^{5}$, R. E. Richardson ${ }^{1}$

1. E. I. du Pont de Nemours and Company, Central Research and Development, E400-5207 Exp. Sta., Wilmington DE, $19880-0400$.

2. E. I. du Pont de Nemours and Company, Fluoroproducts, E352 Experimental Station, Wilmington, DE, 19880-0352.

3. E. I. du Pont de Nemours and Company, Electronic Technologies, US Rt. 23 South \& DuPont Road, Circleville, OH 43113.

4. E. I. du Pont de Nemours and Company, Packaging and Industrial Polymers, E323/302 Exp. Sta., Wilmington, DE, $19880-0323$.

5. E. I. du Pont de Nemours and Company, DuPont Photovoltaic Solutions, BMP30/1258, Wilmington DE, 19880

\section{ABSTRACT}

As part of our research on materials for concentrator photovoltaics (CPV), we are evaluating the optical properties and solar radiation durability of a number of polymeric materials with potential CPV application. For optical materials in imaging or non-imaging optical systems, detailed knowledge of the wavelength dependent complex index of refraction is important for optical system design and performance. Here we report the index of refraction, optical absorbance and haze results of various polymers of interest for CPV systems.

Fluoropolymers such as polyvinylfluoride $\left(\right.$ Tedlar $^{\circledR}$ PVF Film), which has wide application in crystalline silicon (c-Si) flat plate PV modules, as well as poly(tetrafluoroethylene-co-hexafluoropropylene) (Teflon $^{\circledR}$ FEP Film) and poly(ethylene-co-tetrafluoroethylene) (Tefze ${ }^{\circledR}$ ETFE Film) have desirable optical and physical properties for optical applications such as CPV. Hydrocarbon polymers such as polyvinylbutyral (PVB) sheet such as DuPont ${ }^{\mathrm{TM}}$ PV5200, and the ethylene copolymers such as poly(ethylene-co-vinyl acetate) (EVA) such as Elvax ${ }^{\circledR}$ PV1400, poly(ethylene-co-methacrylic acid metal salt) ionomer sheet such as DuPont ${ }^{\mathrm{TM}}$ PV5300 have applications as encapsulant in $\mathrm{C}-\mathrm{Si}$ and other flat plate PV applications. These materials have both a wide variety of polymer compositions and also additive packages, which affect their optical properties such as the UV absorption edge. Even materials such as Kapton ${ }^{\circledR}$ polyimide films, which are used behind the PV cell for their electrically insulating properties, have optical requirements, and we characterize these materials also.

The detailed optical properties of these materials will be useful for CPV system design of the geometrical optics, optimization of the system's optical throughput, and also provide insights into the system's optical absorption, for example in the UV, where this absorption can impact the radiation durability of the materials.

Keywords: fluoropolymer, ethylene copolymer, polyimide, polyester, index of refraction, optical absorbance, VUV ellipsometry.

\section{INTRODUCTION}

For optical materials in imaging or non-imaging optical systems detailed knowledge of the wavelength dependent complex index of refraction, $\hat{n}(\lambda)=n(\lambda)+i k(\lambda)$ is important for optical system design and performance. The index, $n$, and the extinction coefficient, $k$, (which is directly related to the optical absorbance) give insights into the system optical performance. The index of refraction determines reflectance losses at both air/polymer and polymer/polymer interfaces, and is important for matching or optimizing the numerical aperture (NA) of the reducing optical system at all points in the optical path. The extinction coefficient is critical to determine optical losses in the system including the passage of ultraviolet (UV) through the system. The optical absorption of UV light by the materials can contribute to optical degradation of the materials and reduced performance over time. Here we report index of refraction, optical absorbance and haze results for multiple materials of interest for CPV systems.

We have previously studied ${ }^{1}$ Teflon $^{\circledR}$ AF, an amorphous perfluoro-2,2-dimethyl-1,3-dioxole / tetrafluoroethylene (PDD/TFE) copolymer with optical applications as a photomask pellicle in IC fabrication. We found that the optical properties of the three grades of Teflon ${ }^{\circledR}$ AF varied systematically with the AF TFE/PDD composition. Teflon ${ }^{\circledR}$ AF has one of the lowest index of refraction and shortest wavelength optical absorption edges known for a polymer, but in other research we developed other novel fluoropolymers with even shorter wavelength optical absorption edges. ${ }^{2}$ We have also studied amorphous and crystalline silica $^{3}$ and other oxides and nitrides, polystyrene ${ }^{4}$ and novel backbone polymers such as the polysilanes ${ }^{5}$.

For potential CPV applications we report the optical properties of various fluoropolymers, hydrocarbon polymers, and polyimides. The detailed optical properties of these materials will be useful for CPV system design of the geometrical optics, optimization of the system's optical throughput, and also provide insights into the system's optical absorption. This is important for example in the UV, where this absorption can impact the radiation durability of the materials.

This paper describes the optical properties, such as spectral index of refraction, optical absorbance and haze. We have determined these optical properties and found the relationship between those properties for the above materials. 


\section{EXPERIMENTAL METHODS}

\section{$2.1 \quad$ Materials}

Fluoropolymers (FP): Films of tetrafluoroethylenehexafluoropropylene copolymer (Teflon ${ }^{\circledR}$ FEP 500A), ethylene-tetrafluoroethylene copolymer $\left(\right.$ Tefzel $^{\circledR}$ ETFE 500LZ), and polyvinylfluoride (Tedlar ${ }^{\circledR}$ PVF TR10AH9 and UT20BG3) were obtained from DuPont Fluoroproducts. The use of these materials in conventional PV modules is well documented ${ }^{6}$.

Hydrocarbon polymers (HCP): DuPont ${ }^{\mathrm{TM}}$ PV5200 PVB and DuPont ${ }^{T M}$ PV5300 lonomer sheet and Elvax ${ }^{\circledR}$ PV1400 resin were obtained from DuPont Packaging and Industrial Polymers. Films of different thickness were made by melt pressing.

Polyimides (PI): Kapton ${ }^{\circledR} \mathrm{H}$; Kapton $^{\circledR} \mathrm{HN}$ and Kapton $^{\circledR}$ E; were obtained from DuPont Electronic Technologies.

Since the results of the haze measurement vary with the film thickness, we include in Table 1 the thicknesses of the samples used for Haze measurements.

\begin{tabular}{|c|c|c|c|c|}
\hline \multicolumn{5}{|c|}{ Table 1 Sample thickness $(t)$ in mils (0.001"). } \\
\hline FP & $\begin{array}{c}\text { Tedlar }^{\circledR} \\
\text { PVF } \\
\text { UT20BG3 }\end{array}$ & $\begin{array}{c}\text { Tedlar }^{\circledR} \\
\text { PVF } \\
\text { TR10AH9 }\end{array}$ & $\begin{array}{c}\text { Tefzel }^{\circledR} \\
\text { ETFE }\end{array}$ & Teflon $^{\circledR}$ FEP \\
\hline $\mathrm{t}$ & 2 & 1 & 2 & 2 \\
\hline HCP & $\begin{array}{c}\text { PV1400 } \\
\text { EVA }\end{array}$ & \multicolumn{2}{|c|}{$\begin{array}{c}\text { PV5200 } \\
\text { PVB }\end{array}$} & $\begin{array}{l}\text { PV5300 } \\
\text { Ionomer }\end{array}$ \\
\hline$t$ & 10 & \multicolumn{2}{|c|}{10} & 10 \\
\hline $\mathrm{PI}$ & Kapton $^{(\Theta)} \mathrm{H}$ & \multicolumn{2}{|c|}{ Kapton $^{(B)} \mathrm{HN}$} & Kapton $^{\circledR} \mathrm{E}$ \\
\hline $\mathrm{t}$ & 2 & \multicolumn{2}{|c|}{2} & 2 \\
\hline
\end{tabular}

\subsection{Spectroscopic Ellipsometry}

Variable angle spectroscopic ellipsometry (VASE) measurements were performed with a VUV-VASE ${ }^{\circledR}$ VU302 instrument by J. A. Woollam Co. ${ }^{7}$, which has a range from 0.69 to $8.55 \mathrm{eV}$ (1800 to $145 \mathrm{~nm}$ ), and employs $\mathrm{MgF}_{2}$ polarizers and analyzers rather than the more common calcite optics. The spectrometer was upgraded from single beam to dual beam for more accurate transmission measurements and better instrument stability. The instrument has a $\mathrm{MgF}_{2}$ auto-retarder and is fully nitrogen purged to avoid absorption of VUV light by ambient oxygen and water vapor which is important at wavelengths below $200 \mathrm{~nm}$. Light from both the deuterium lamp and the xenon lamp passes through a double-chamber Czerny-Turner type monochromator to provide wavelength selection and stray-light rejection. The spot diameter of light source on the surface of the sample is $2 \mathrm{~mm}$. Computer-controlled slit widths can adjust the bandwidth to insure adequate spectral resolution of optical features in the data such as the closely spaced interference oscillations, which arise in very thick film. A photomultiplier tube is utilized for signal detection in the ultraviolet. A stacked $\mathrm{Si} / \mathrm{InGaAs}$ photodiode detector is used for longer wavelengths. Ellipsometric measurements were conducted using light incident at angles of $65^{\circ}$ to $75^{\circ}$ relative to normal on the front surface of the sample, the back of which was roughened with coarse polishing paper. The instrument measures the ellipsometric parameters $\Psi$ and $\Delta$, which are defined by Equation $1^{8}$,

$$
\tan (\Psi) e^{i \Delta}=\frac{R_{P}}{R_{S}}
$$

where $R_{P} / R_{S}$ is the complex ratio of the $p$ - and s-polarized components of the reflected amplitudes. These parameters are analyzed using the Fresnel equations ${ }^{9}$ in a computer-based modeling technique including a surface roughness layer to directly determine the optical constants. $^{10,11}$ VUV-VASE ${ }^{\circledR}$ VU-302 measurements for this experiment were taken from wavelength range $145 \mathrm{~nm}$ to $1650 \mathrm{~nm}$ and at multiple angles of incidence $\left(65^{\circ}-759\right.$. Variable angles improve confidence, as light travels different paths through the film.

The ellipsometry data, taken from the film, was fit to determine the polymer film roughness, thickness nonuniformity, and complex refractive index. ${ }^{12}$ An optical model was used to describe the film optical constants over the wide spectral range.

The film is modeled using tabulated optical constants from Woollam. A thin surface layer was described in the optical model using roughness, which is an effective medium approximation (EMA) consisting of 50/50 mix of organic film and void $(n=1)$. In the initial stage a Cauchy dispersion model was used to fit the transparent region of $450 \mathrm{~nm}$ to $1550 \mathrm{~nm}$. Then the model was determined by fitting the optical constants on a point-by-point basis over the full spectral range in which the data in each single wavelength are fit separately. Finally the $n$ and $k$ are matched and the data is fitted using a Genosc ${ }^{\mathrm{TM}}$ layer (Equation 2) $^{13}$.

$$
\hat{n}=n+i k
$$

\subsection{Optical Absorbance and Haze}

The optical absorbance was determined by center mount absorbance method (Figure 1) using a Cary 5000 UV-Vis-NIR spectrophotometer (Varian) for free standing films. The measured value of absorbance was divided by the film thickness to obtain a value of optical absorbance per $\mathrm{cm}$ (base 10).

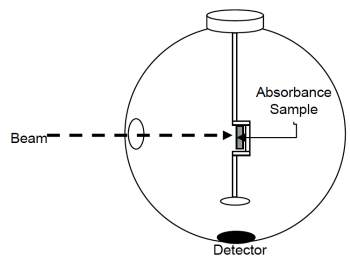

Figure 1. Center mount absorbance method. 
For films coated on a substrate, once the transmission spectra of the film were determined, the film's optical absorbance per $\mathrm{cm}$ (base 10) could be determined by

$$
A / \mathrm{cm}=\frac{\log _{10}\left[T_{\text {substrat }} / T_{\text {film }}\right]}{t_{\text {film }}}
$$

where $T$ is the transmission and $t$ is the thickness of the film and $A / \mathrm{cm}$ is the absorbance per centimeter. Using multiple samples of different film thickness one can then solve the resulting system of equations and determine the reproducibility and a standard deviation of the optical absorbance per centimeter.

The calculation of optical absorbance assumes that the film is of homogenous composition and uniform thickness. Therefore an integrating reflectance accessory is required and the reflectance measured is predominately specular ${ }^{14}$. Transmission based measurements also require that the film thickness of the sample on the substrate be optimized for the dynamic range of the technique so that the transmittance of the film falls in the range from 3 to $90 \%$. If the transmittance falls much below $1 \%$, the accuracy of the measurement is severely degraded and erroneous results appear ${ }^{15}$.

The Cary 5000 UV-Vis-NIR spectrophotometer (Varian) is also used for the haze measurement. The

\begin{tabular}{|c|c|c|c|c|}
\hline \multicolumn{5}{|c|}{ Table 2 Index of refraction (n) at d-line (589.3nm). } \\
\hline FP & $\begin{array}{c}\text { Tedlar }^{\circledR} \\
\text { PVF } \\
\text { UT20BG3 }\end{array}$ & $\begin{array}{c}\left.\text { Tedlar }^{(}\right) \\
\text {PVF } \\
\text { TR10AH9 }\end{array}$ & $\begin{array}{c}\text { Tefzel }^{\circledR} \\
\text { ETFE }\end{array}$ & $\begin{array}{c}\text { Teflon }^{\circledR} \\
\text { FEP }\end{array}$ \\
\hline Index & 1.474 & 1.478 & 1.398 & 1.350 \\
\hline HCP & PV1400 & PV5200 & $\begin{array}{c}\text { PV5300 } \\
\text { lonomer }\end{array}$ \\
\hline Index & EVA & PVB & 1.487 \\
\hline PI & Kapton $^{\circledR} \mathrm{H}$ & Kapton $^{(8)} \mathrm{HN}$ & Kapton $^{(8)} \mathrm{E}$ \\
\hline Index & 1.824 & \multicolumn{1}{|c|}{1.817} & 1.899 \\
\hline
\end{tabular}

instrument utilizes a hemispherical optical measuring system, with an integrating sphere, in which the specimen is placed flush against the sphere port. A unidirectional illumination with diffuse viewing geometry was used. The transmission (total and scattered) and reflectance (diffuse + specular and diffuse only) (defined in Figure 2) were measured based on ASTM D 1003 procedure B (Figure 3). The following Equation was used to calculate the percent haze:

$$
\text { Haze }=T_{d} / T_{t} \times 100
$$

Where $T_{d}$ is the diffuse transmittance and $T_{t}$ is the total transmittance.

The above measurements were conducted under the following conditions: The external DRA-2500 was installed into the spectrophotometer and aligned. UV-Vis-NIR spectra were, in general, acquired in the region 200-2500 $\mathrm{nm}$ using appropriate baseline correction (zero/baseline for \% $\%$ and absorbance, zero $x$ standard reference for reflectance, correction for spectral only). Indicative instrumental parameters were as follows: spectral bandwidth (SBW): $4 \mathrm{~nm}$; averaging time: $0.4 \mathrm{sec}$; data interval: $2 \mathrm{~nm}$; double beam mode using full slit height for $\% \mathrm{~T}$ and absorbance, reduced for \%R; a mask over the sample port was used with a reduced slit for the reflectance data; the mask is in place during baseline and sample collection; NIR energy: 75 - 100; a small spot kit (SSK) was used for the center mount absorbance data (not reflectance).

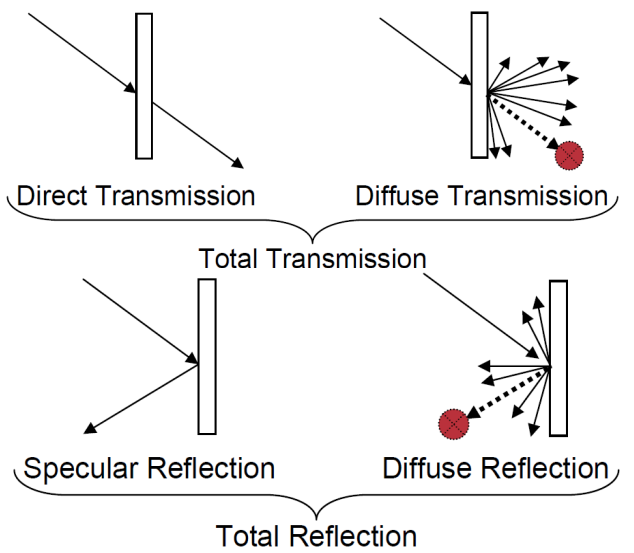

Figure 2. The components of the Total Transmittance and Total Reflectance.

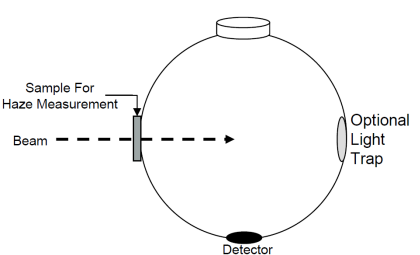

Figure 3. ASTM D 1003 procedure B for Haze measurement utilizing unidirectional illumination with diffuse viewing geometry

As in all experimental measurements, the accuracy of the measured values is a function of the sample and measurement apparatus. The inherent sensitivity of spectral transmission and absorbance measurements is affected by the optical path length of the sample, and the transmission drop that occurs as light transmits through the sample. As the transmission drop decreases, the accuracy of absorbance measurement decreases. A transmission difference of $\sim 0.1 \%$ is near the limit of the measurement method.

\section{RESULTS AND DISCUSSION}

Now we present results on the spectral index of refraction (Table 2), the absorbance per centimeter and the haze of the materials of interest. The refractive index ( $n$ and $k$ ) and transmission intensity of materials of potential interest to CPV were determined over the wavelength range $145 \mathrm{~nm}$ to $1650 \mathrm{~nm}$. 


\subsection{Fluoropolymers (FP)}

\subsubsection{Index of Refraction}

The index of refraction versus wavelength for the fluoropolymers studied is shown in Figure 4 . Their values at the sodium D-line are also summarized in Table 2. The lowest index of refraction corresponds to Teflon ${ }^{\circledR}$ FEP which is a completely fluorinated material. As the amount of fluorocarbon decreases in the other polymers the index increases as expected. Tefzel ${ }^{\circledR}$ ETFE is an approximately alternating copolymer of ethylene and tetrafluoroethylene which results in a fluorine content of about 59 weight percent. Tedlar ${ }^{\circledR}$ PVF has the lowest fluorine content of the three at 41 weight \%.

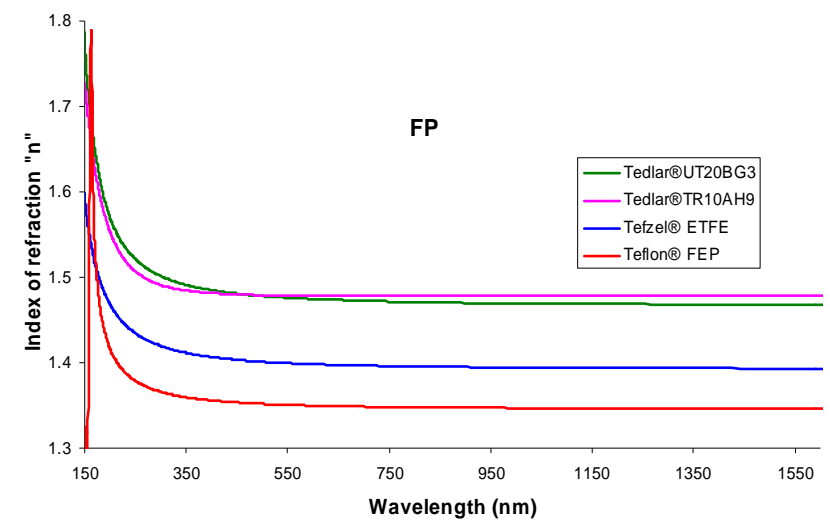

Figure 4. Index of refraction $\mathbf{n}$ determined from ellipsometric data for fluoropolymers.

These fluoropolymers exhibit normal dispersion, defined as the fact that the index of refraction is seen to increase as the wavelength decreases, down to wavelengths below $200 \mathrm{~nm}$. Normal dispersion is observed as the wavelength of the light approaches the fundamental absorption edge. ${ }^{16}$

\subsubsection{Abs/cm \& Haze:}

The Abs/cm and haze of the fluoropolymers are shown in Figure 5 and Figure 6 respectively. The fundamental absorption edge of Teflon ${ }^{\circledR}$ FEP and Tefzel ${ }^{\circledR}$ ETFE is at wavelengths below $200 \mathrm{~nm}$ and therefore the Abs/cm is very low at all solar wavelengths. Tedlar $^{\circledR}$ PVF TR10AH9 film shows an absorption edge below $300 \mathrm{~nm}$ while Tedlar $^{\circledR}$ PVF UT20BG3 film essentially blocks most radiation at wavelengths below $400 \mathrm{~nm}$. Its $\mathrm{Abs} / \mathrm{cm}$ at higher wavelengths is still very low and comparable to the other fluoropolymers. Even though all the fluoropolymers studied here are semicrystalline materials, only films of Tedlar $^{\circledR}$ PVF UT20BG3 exhibit significant haze. Teflon ${ }^{\circledR}$ FEP, Tefzel ${ }^{\circledR}$ ETFE and Tedlar ${ }^{\circledR}$ PVF TR10AH9 films are very clear and show much less haze than that one UV opaque Tedlar grade.

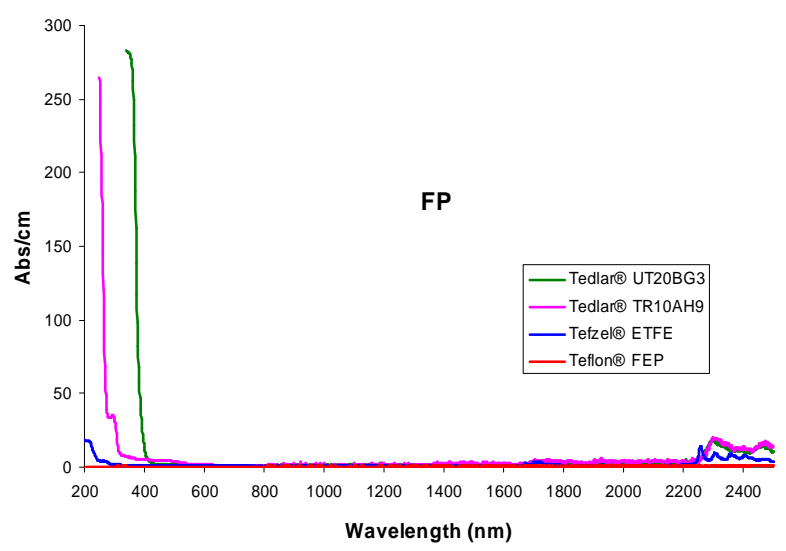

Figure 5. Optical absorption of fluoropolymer films

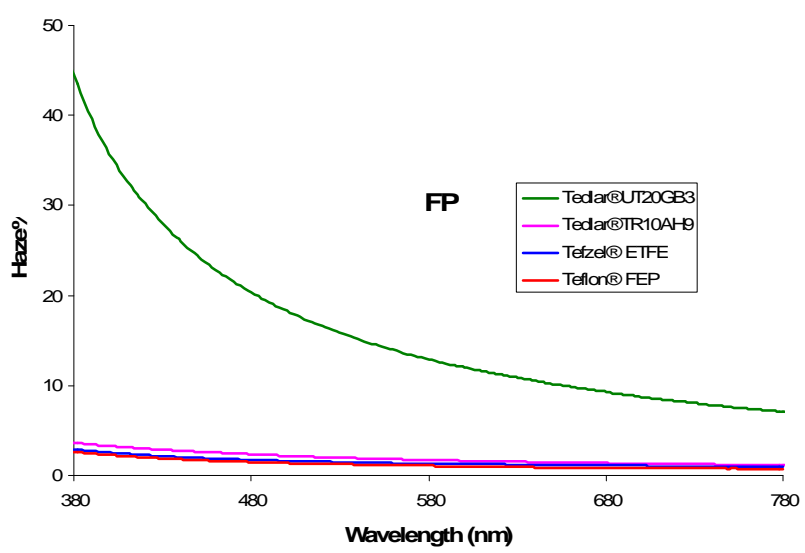

Figure 6. Haze of fluoropolymer films

\subsection{Hydrocarbon Polymers (HCP)}

Hydrocarbon polymers such as the ethylene copolymers with vinyl acetate are widely used as encapsulants in PV.

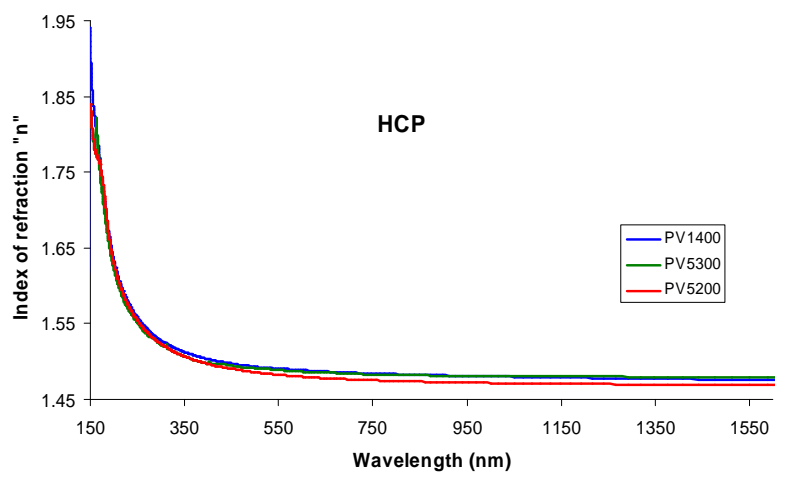

Figure 7. Index of refraction $\mathbf{n}$ determined from ellipsometric data for hydrocarbon polymers .

\subsubsection{Index of Refraction}

Their index of refraction versus wavelength is shown in Figure 7. All of them have very similar index over the 
wavelength range measured. PV1400, a copolymer of ethylene and vinyl acetate commonly used in encapsulant formulations for flat plate c-Si PV, shows a slightly higher index than the other two. DuPont ${ }^{\text {TM }}$ PV5200, polyvinylbutyral commonly used in thin-film PV, has the lowest index of refraction.

\subsubsection{Abs/cm \& Haze}

The absorption and haze of the hydrocarbon polymer samples are shown in Figure 8 and Figure 9. Elvax ${ }^{\circledR}$ PV1400 is an unformulated ethylene-vinyl acetate resin. It does not contain any UV stabilizing additives and therefore shows a shorter wavelength absorption edge than the DuPont $^{\mathrm{TM}}$ PV5200 PVB and DuPont ${ }^{\mathrm{TM}}$ PV5300 ionomer encapsulants, which are fully formulated products. In addition, Elvax ${ }^{\circledR}$ PV1400, and DuPont ${ }^{\mathrm{T}}$ PV5200 PVB exhibit some haze at these film thicknesses. DuPont ${ }^{T M}$ PV5300 ionomer films are very clear and have the lowest haze of all these encapsulants.

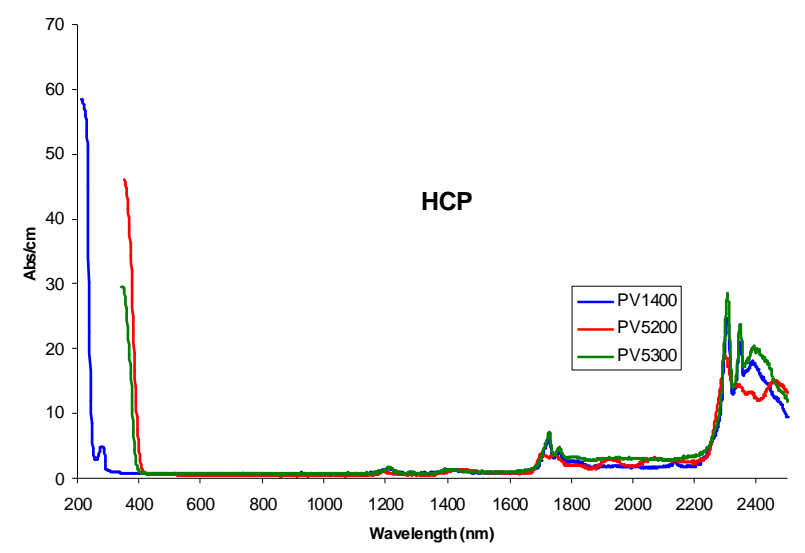

Figure 8. Optical absorption of hydrocarbon polymers

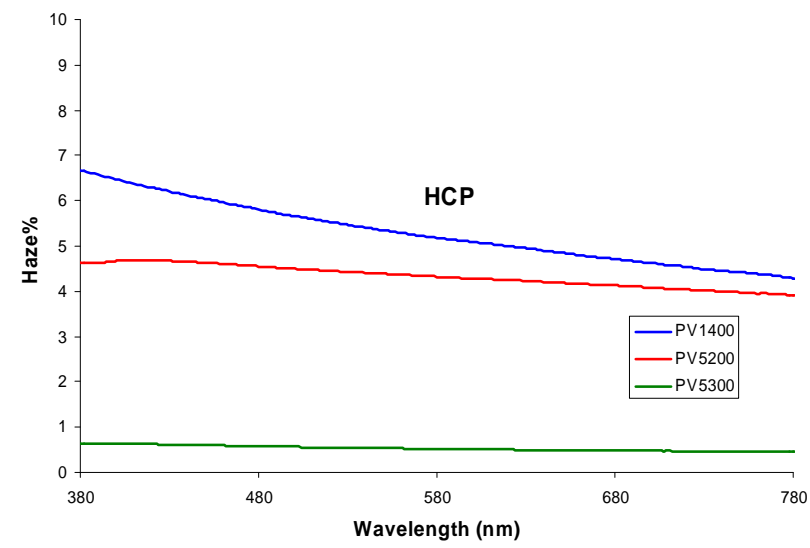

Figure 9. Haze of hydrocarbon polymer films

\subsection{Polyimides (PI)}

Polyimides are most commonly used behind PV cells for thermal management and other purposes, and are therefore screened from direct sunlight. However, their optical properties are still of interest for other potential applications in the PV industry.

\subsubsection{Index}

Figure 10 shows the index of refraction versus wavelength for three different polyimides. As expected of polymers with an aromatic backbone, the index of refraction is much higher than that of the other polymers in this study. Kapton ${ }^{\circledR}$ E shows the highest index refraction of all polyimides.

Here we observe both normal dispersion (index increases with decreasing wavelength) and also anomalous dispersion ${ }^{16}$ where, for wavelengths of light that are shorter than the fundamental absorption edge of the material, the index is seen to decrease with decreasing wavelength.

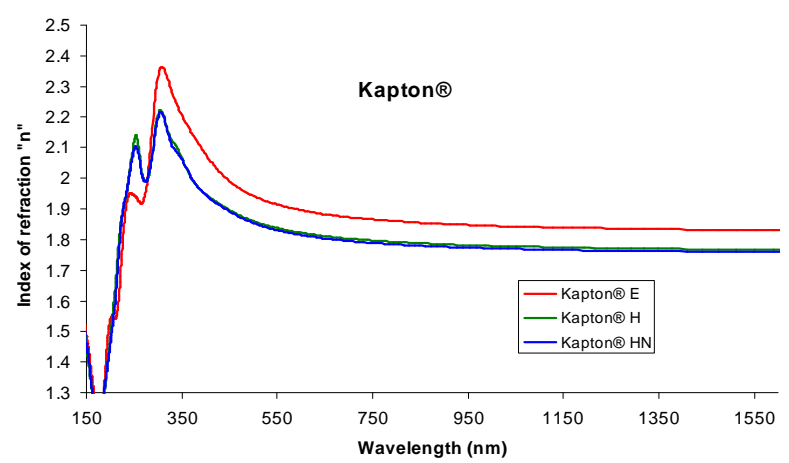

Figure 10. Index of refraction $\mathbf{n}$ determined from ellipsometric data for Polyimides.

\subsubsection{Abs/cm \& Haze}

The abs/cm and haze of the polyimide polymers are shown in Figure 11 and Figure 12. The fundamental absorption edge of Kapton ${ }^{\circledR} \mathrm{H}$; Kapton ${ }^{\circledR} \mathrm{HN}$ and Kapton ${ }^{\circledR} \mathrm{E}$ are at similar wavelengths, and can be associated with the visual yellow color of these materials. The higher haze in the Kapton ${ }^{\circledR} \mathrm{HN}$ can be associated with additives.

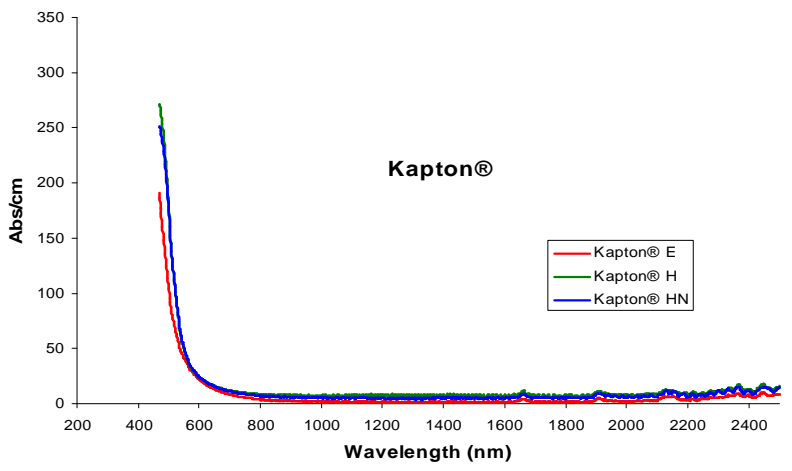

Figure 11. Optical absorption of polyimides 


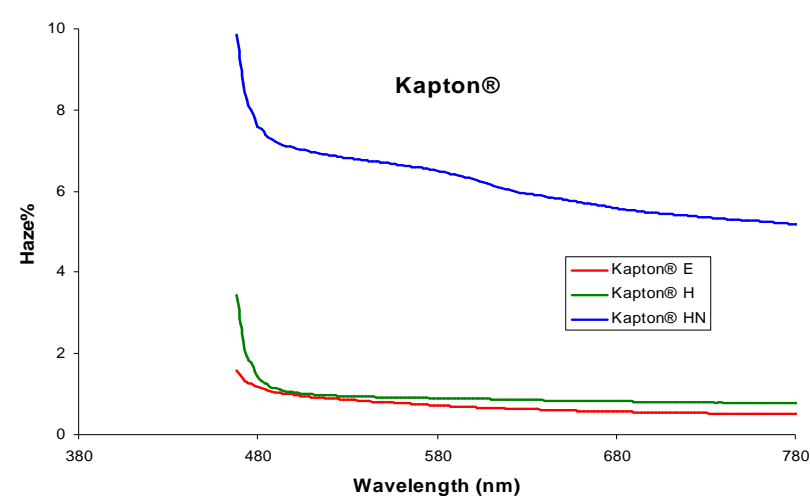

Figure 12. Haze of polyimide films

\section{CONCLUSIONS}

Three groups of polymers including ten materials have been studied using ellipsometry and transmission measurements to determine their optical properties. These materials have differing compositions and additives which give rise to systematic changes in the optical properties such as the index of refraction and optical absorbance. The unique optical properties of these materials make them suitable for various applications in the photovoltaic's industry.

\section{ACKNOWLEDGEMENTS}

The authors acknowledge the assistance of Barbara. B French for editing the manuscript and Greg Pribil (J.A. Woollam Co.) for ellipsometric analysis.

\section{REFERENCES}

[1] M K. Yang, R. H. French, E. W. Tokarsky, Journal of Micro/Nanolithography, MEMS and MOEMS, 7, 3, 033010, 1-9, (2008).

[2] R. H. French, R. C. Wheland, W. Qiu, M. F. Lemon, E. Zhang, J. Gordon, V. A. Petrov, V. F. Cherstkov, N. I. Delaygina, Journal of Fluorine Chemistry, 122, 6380, (2003).

[3] G. L. Tan, M. F. Lemon, R. H. French, D. J. Jones, "Optical properties and London Dispersion Forces of Amorphous and Crystalline Silica Determined by Vacuum Ultraviolet Spectroscopy and Spectroscopy Ellipsometry", Physical Review B, 72, 205117, p. 1$10,(2005$

[4] R. H. French, K. I. Winey, M. K. Yang, W. Qiu, Australian, "Optical Properties, Electronic Structure and Dispersion Interactions of Polystyrene", Australian Journal of Chemistry,60, 251-63, (2007).

[5] R. H. French, J. S. Meth, J. R. G. Thorne, R. M. Hochstrasser, R. D. Miller, Synthetic Metals, 50, 1-3, 499-508 (1992).
[5] M. DeBergalis, Journal of Fluorine Chemistry, 125, 1255-1257, (2004).

[7] J. A. Woollam Co., Inc., 645 M Street, Suite 102, Lincoln, NE 68508 USA.

[8] B. Johs, R. H. French, F. D. Kalk, W. A. McGahan, J. A. Woollam, Optical Interference Coatings, SPIE 2253, 1098 (1994).

[9] J. A. Woollam, B Johs, C. M. Herzinger, J. Hilfiker, R. Synowicki, C. L. Bungay, "Overview of Variable Angle Spectroscopic Ellipsometry (VASE), Part I: Basic Theory and Typical Applications", SPIE, CR72, 3-28, (1999).

[10] M. E. Innocenzi, R. T. Swimm, M. Bass, R. H. French, M. R. Kokta, "Optical Absorption in Undoped Yttrium Aluminum Garnet", Journal of Applied Physics, 68, 3, 1200-4 (1990).

[11] M. E. Innocenzi, R. T. Swimm, M. Bass, R. H. French, A. B. Villaverde, M. R. Kokta, "Room Temperature Optical Absorption in Undoped $\alpha-\mathrm{Al}_{2} \mathrm{O}_{3}$ ", Journal of Applied Physics, 67, 12,7542-46 (1990).

[12] J. A. Woollam, B Johs, C. M. Herzinger, J. Hilfiker, R. Synowicki, C. L. Bungay, "Overview of Variable Angle Spectroscopic Ellipsometry (VASE), Part II: Advanced Applications", SPIE, CR72, 29-58, (1999).

[13] F. Wooten, Optical Properties of Solids, Academic Press, New York, 49, (1972).

[14] Stuart White, Evaluation of the Cary Absolute Specular Reflectance Accessory for the measurement of Optical Constants of Thin Film, Varian, UV-45, June 1988.

[15] R. H. French, R. C. Wheland, D. J. Jones, J. N. Hilfiker, R. A. Synowicki, F. C. Zumsteg, J. Feldman, A. E. Feiring, "Fluoropolymers for 157nm Lithography: Optical Properties from VUV Absorbance and Ellipsometry Measurements", Optical Microlithography XIII, SPIE Vol. 4000, edited by C. J. Progler, 14911502 (2000).

[16] R. H. French, H. Sewell, M. K. Yang , S. Peng, D. McCafferty, W. Qiu, R. C. Wheland, M. F. Lemon, L. Markoya, M. K. Crawford, "Imaging Of 32-nm 1:1 Lines And Spaces Using 193-nm Immersion Interference Lithography With Second-Generation Immersion Fluids To Achieve A Numerical Aperture Of 1.5 And A k1 Of 0.25", Journal of Microlithography, Microfabrication and Microsystems, Topical Issue on Hyper-NA Imaging, 4(3), 031103-1-14, (2005). 